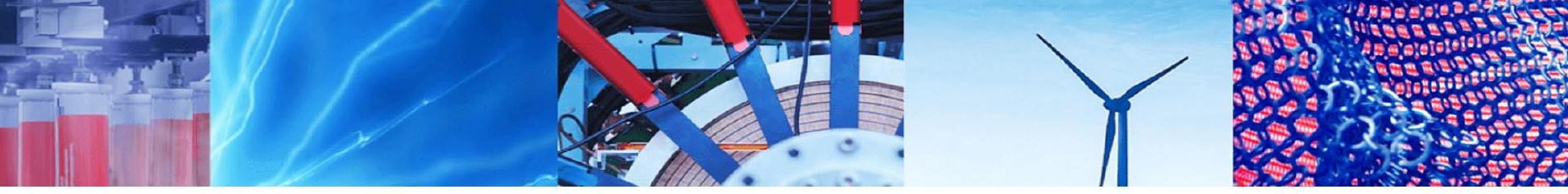

Research Article

\title{
Concrete with an outer plastic protective shell
}

\author{
Nwzad Abduljabar Abdulla ${ }^{1}$
}

Received: 24 February 2020 / Accepted: 13 May 2020 / Published online: 18 May 2020

(c) Springer Nature Switzerland AG 2020

\begin{abstract}
Concrete is a multi-phase complex composite based on cement. The post-peak behavior of concrete is unpredictable and influences the overall performance of the concrete. Engineering plastics used in the present study as a external shell to increase the post-peak deformations of concrete cylinders. The applicability and efficiency of the proposed external plastic shell for concrete cylinders jacketing evaluated experimentally. The protective shell slipped on the concrete cylinders after the curing period. In order to evaluate the individual load contribution of the two components, a small gap of $1.2 \mathrm{~mm}$ introduced between the two and the specimens capped on the top and tested under compression. Test results show a ductile post-peak response with strain-softening and the formation of two peak loads.
\end{abstract}

Keywords Engineering plastic · Protection shell · Concrete core · Ductility · Peak load

\section{Introduction}

In the last few decades, there has been great interest in combination of concrete with other materials for use in construction and infrastructure applications. Most of the research has covered the role of Fiber-reinforced polymers (FRP). One major disadvantage of these composites is the cost of material and labor [1-3]. Other alternative materials that are more economical in terms of manufacture, labor, and construction might be more attractive to use in certain applications. Laboratory experimental testing is a useful tool to quantify the mechanical properties, material characteristics, and performance of concrete encased with more economical materials. External thermoplastic shell may be used to improve constructability and produce a more durable final product. The shell may be a plastic PVC tube slipped on the column just after form removal. Such plastics are also useful tools for preventing steel degradations and concrete deteriorations caused by physical and chemical attacks from surrounding environments. Thermoplastic polymers with repeated molecule chains are changeable for the better, expanding product possibilities and facilitating its recycling. The tube, with its density nearly half the density of concrete, considered as a lightweight material. The yield strength and elastic modulus of the plastic tube are $1 / 6$ and $1 / 50$ of that for steel tube, $248 \mathrm{MPa}$, and $191 \mathrm{GPa}$ respectively [4], for similar tube thickness.

A concrete covered with polymeric materials will yield superior thermal and electrical insulation properties. Mechanical properties of the plastic tube, such as elongation, have been the driving force for some studies on this material since the early attempts by Kurt [5] for use in concrete structures. For a steel-reinforced concrete column, the PVC tube acts as additional reinforcement in the axial and hoop directions [6]. PVC tube confinement could reduce the effect of recycled aggregate (RA) quality on the variability of RA concrete axial behavior under compression load [7]. Circular PVC tubes have comparatively high energy absorbing capacities and feature a favorable stroke length per unit mass [8].

A special PVC joint designed for bamboo double layer grids was investigated [9]. Test results demonstrated the suitability of the system for constructing lightweight

Nwzad Abduljabar Abdulla, anwzad@yahoo.com | 'Salahaddin University, Kirkuk Rd., Erbïl, Iraq. 
medium-span bamboo structures with excellent structural attributes. Concrete members encasing PVC tubes were examined for reliability assessment to optimize the size of elements like columns by lightening the weight of beams [10]. Reinforced concrete deep beams with embedded PVC tubes were tested under three-point loads to failure [11]. For a tube diameter $1 / 3$ of the beam width, the effect on the capacity and rigidity of the beam was limited. For larger diameters, the load capacity decreased from 16.7-33.3\%; however, the reduction in stiffness was between 103 and 297\%. The plastic tube was used as an inner shell in concrete-filled double-skinned tubular columns with an external octagon shaped steel tube tested under axial compression load [12]. The outer steel tube and core concrete exhibited different types of destruction phenomenas, whereas the inner PVC-U tube did not suffer destruction. UPVC is resistant to acids and alkalis. Experimental results for the axial failure of thin-walled sections made of polymeric plastic were used for assessing its suitability for concrete protection in hostile environments [13].

In another study, the plastic tube used for concrete cylinder protection in aggressive environments. The range of strength deterioration was changed from $45-50 \%$ for unprotected concrete cylinders to $0.3-1 \%$ for the protected specimens [14]. The plastic shell was proposed for extending the service life of compression members in structures exposed to severe environments [15]. Concrete filled plastic tube (CFPT) introduced as an alternative for the regular column for polyhouse in the aggressive environment [16] and small residential buildings [17].

The PVC tube can embed and provide sufficient protection for fiber reinforced polymer wraps against any chemical effects of fresh concrete [18]. In practice, the protective shell could slip on the concrete compression member just after form removal. In order to assess the mechanical performance of the system under axial compression load, previous studies investigated the composite contributions of the plastic tube and infill concrete, whereby the plastic tube was used as a pour-in form for infill concrete [19-22]. The current study investigates the individual contribution of the two components by introducing a small gap of 1.2 $\mathrm{mm}$ between the plastic tube and infill concrete and which has not been investigated previously. The proposed system may be used in infrastructure applications such as bridge piers and piles.

\section{Experiment}

\subsection{Materials}

Standard Portland cement similar to Type I Portland cement (ASTM) (C150-89) with a specific gravity of 3.15 was used. The fine aggregate was river sand from the Eski kalak, area north of Iraq. Its specific gravity was 2.6. The normal coarse aggregate was from the same source with a maximum specific gravity of 2.65 . The crushed coarse aggregate, from a mountainous origin, had the same size with a maximum specific gravity of 2.7 .

\subsection{Mixing}

A rotary drum concrete mixer with a capacity of $0.07 \mathrm{~m}^{3}$ used for mixing the ingredients. A portion of mixing tap water added to the mixer, then half of coarse aggregate and sand, followed by the cement, and then the remaining aggregates. The mixer stopped after 3 min of mixing, and the remaining water added, and it was further mixed for another $3 \mathrm{~min}$. The concrete cast into steel molds in two layers, and each layer vibrated. Different concrete mixes used to produce the desired compressive strengths and a slump of $100 \pm 10 \mathrm{~mm}$.

\subsection{Specimens}

UPVC tubes with solid wall construction made up of two white layers and one blue layer in-between, with overall diameters of $110 \mathrm{~mm}$ and thickness of $3.6 \mathrm{~mm}$, were cut using an electrical sawing machine, and the end's ground (Fig. 1). Six mixtures used to cast the six groups of specimens. Each group had six standard concrete cylinders. After 28 days of curing, three cylinders from each group clothed with the protective plastic. The concrete cylinders (C) with a diameter of $100 \mathrm{~mm}$ could easily slip into the protective plastic jackets (OJ) which had an internal diameter of $102.4 \mathrm{~mm}$ (Fig. 2) to form (C-OJT) specimens or the concrete with an outer plastic protective shell. To remove unevenness, the C-OJT specimens capped at the top only with a special hydraulic powder (Fig. 3). The bottom of C-OJT, usually even and remained uncapped (Fig. 4). The mixture details and designation of all the specimens summarized in Table 1. For example, C-OJT6-1, where $\mathrm{C}$ stands for concrete, OJ stands for the outer protective jacket, $\mathrm{T}$

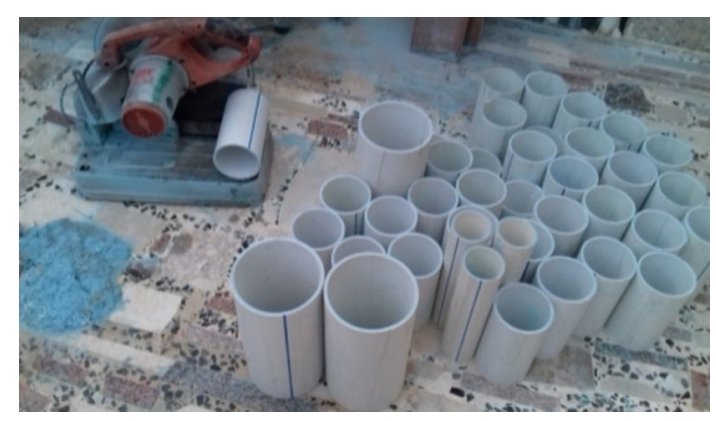

Fig. 1 Handling of plastic tubes 


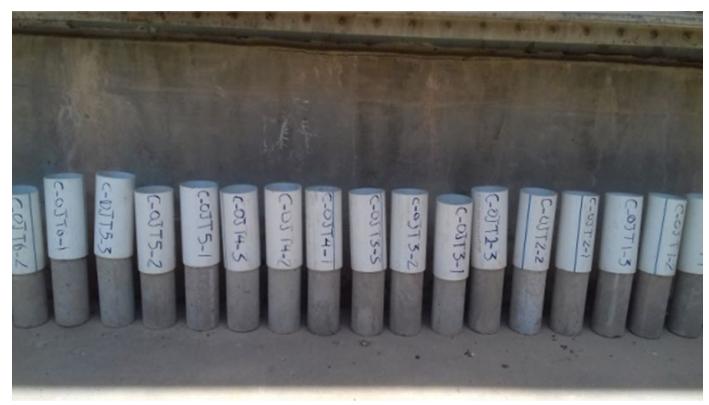

Fig. 2 Cylinders slipped into a plastic jacket

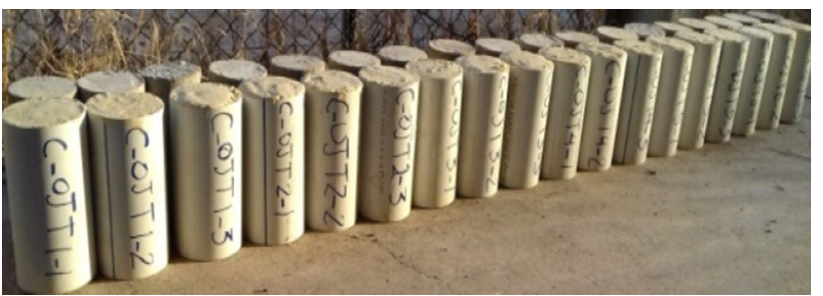

Fig. 3 Capping of top of C-OJT specimens

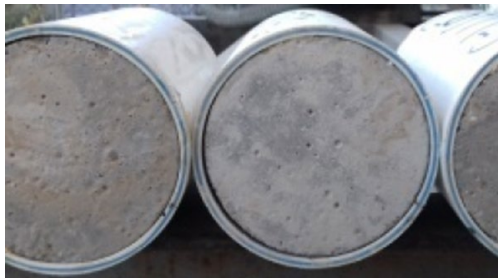

Fig. 4 Uncapped bottom of C-OJT

expresses plastic tube, 6 means group number, and 1 stand for specimen number one in the group. Additionally, two specimens (C-OJT7-1, C-OJT7-2) had a gap of 20 $\mathrm{mm}$ at the top (Fig. 5) and the concrete mixture was similar to mix 3 and 4 (Table 1).

\subsection{Testing and failure type}

The coupons for tensile testing of PVC were machined down to a constant thickness of $2.5 \mathrm{~mm}$ (Fig. 6). An electronic universal testing apparatus used to test the coupons (Fig. 7), as per ASTM D638. The yield strength and tensile strength found to be $40 \mathrm{MPa}$ and $57.2 \mathrm{MPa}$, respectively. Physical testing of the actual tube for mechanical characteristics is essential (Fig. 8). The deformation mode was local plastic buckling of thin-walled tube at upper end due to large stress concentrations. The plastic tube under compression load reached yield and ultimate strength of 40.5 MPa and $56.6 \mathrm{MPa}$, respectively. For C-OJT specimens,
Table 1 Mix proportions and test values

\begin{tabular}{|c|c|c|c|c|}
\hline Specimen & Mix ratio & Agg. type & fco (MPa) & $\mathrm{N}_{\mathrm{EX}}(\mathrm{KN})$ \\
\hline C-OJT1-1 & $1: 2: 4$ & 20. N & - & 312.6 \\
\hline$C-1-1$ & $1: 2: 4$ & 20. N & 27.4 & - \\
\hline C-OJT1-2 & $1: 2: 4$ & 20. N & - & 318.9 \\
\hline$C-1-2$ & $1: 2: 4$ & 20. N & 27.4 & - \\
\hline C-OJT1-3 & $1: 2: 4$ & $20 . \mathrm{N}$ & - & 310.2 \\
\hline$C-1-3$ & $1: 2: 4$ & 20. N & 27.4 & - \\
\hline C-OJT2-1 & $1: 2: 4$ & 20. C & - & 323.5 \\
\hline$C-2-1$ & $1: 2: 4$ & 20. C & 28.2 & - \\
\hline C-OJT2-2 & $1: 2: 4$ & 20. $C$ & - & 320.0 \\
\hline$C-2-2$ & $1: 2: 4$ & 20. C & 28.2 & - \\
\hline C-OJT2-3 & $1: 2: 4$ & 20. $C$ & - & 327.2 \\
\hline$C-2-3$ & $1: 2: 4$ & 20. $C$ & 28.2 & - \\
\hline C-OJT3-1 & $1: 1.5: 3$ & 20. N & - & 329.0 \\
\hline$C-3-1$ & $1: 1.5: 3$ & $20 . \mathrm{N}$ & 30.25 & - \\
\hline C-OJT3-2 & $1: 1.5: 3$ & $20 . \mathrm{N}$ & - & 328.4 \\
\hline$C-3-2$ & $1: 1.5: 3$ & $20 . \mathrm{N}$ & 30.25 & - \\
\hline C-OJT3-3 & $1: 1.5: 3$ & 20. N & - & 339.8 \\
\hline$C-3-3$ & $1: 1.5: 3$ & $20 . N$ & 30.25 & - \\
\hline C-OJT4-1 & $1: 1.5: 3$ & 20. C & - & 350.3 \\
\hline$C-4-1$ & $1: 1.5: 3$ & 20. C & 31.6 & - \\
\hline C-OJT4-2 & $1: 1.5: 3$ & 20. C & - & 354.6 \\
\hline$C-4-2$ & $1: 1.5: 3$ & 20. C & 31.6 & - \\
\hline C-OJT4-3 & $1: 1.5: 3$ & 20. C & - & 344.1 \\
\hline$C-4-3$ & $1: 1.5: 3$ & 20. C & 31.6 & - \\
\hline C-OJT5-1 & $1: 1: 2$ & $20 . \mathrm{N}$ & - & 341.9 \\
\hline$C-5-1$ & $1: 1: 2$ & $20 . \mathrm{N}$ & 31.4 & - \\
\hline C-OJT5-2 & $1: 1: 2$ & 20. N & - & 338.2 \\
\hline$C-5-2$ & $1: 1: 2$ & $20 . N$ & 31.4 & - \\
\hline C-OJT5-3 & $1: 1: 2$ & 20. N & - & 347.7 \\
\hline$C-5-3$ & $1: 1: 2$ & $20 . \mathrm{N}$ & 31.4 & - \\
\hline C-OJT6-1 & $1: 1: 2$ & 20. C & - & 356.5 \\
\hline$C-6-1$ & $1: 1: 2$ & 20. C & 32.72 & - \\
\hline C-OJT6-2 & $1: 1: 2$ & 20. C & - & 361.7 \\
\hline$C-6-2$ & $1: 1: 2$ & 20. C & 32.72 & - \\
\hline C-OJT6-3 & $1: 1: 2$ & 20. C & - & 371.3 \\
\hline$C-6-3$ & $1: 1: 2$ & 20. C & 32.72 & - \\
\hline C-OJT7-1 & $1: 1.5: 3$ & 20. N & - & 314.1 \\
\hline$C-3-2$ & $1: 1.5: 3$ & 20. N & 30.25 & - \\
\hline C-OJT7-2 & $1: 1.5: 3$ & 20. C & - & 325.9 \\
\hline$C-4-2$ & $1: 1.5: 3$ & 20. C & 31.6 & - \\
\hline
\end{tabular}

two electrical resistance strain gauges were attached to the external surface of the tube at the mid-height in longitudinal and horizontal directions.

Two Linear variable differential transducers (LVDT) were used in the experiment to record the axial deformation of the specimens under increasing axial compression load, with a low rate of plate displacement $(0.01 \mathrm{~mm} / \mathrm{s})$. Additionally, two LVDT was used to record the lateral 
Fig. 5 Specimen C-OJT7-1 with $20 \mathrm{~mm}$ gap

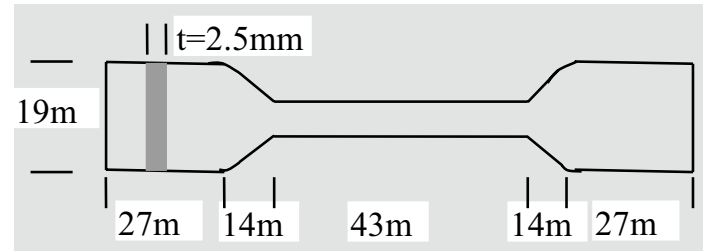

Fig. 6 Coupons for tensile testing

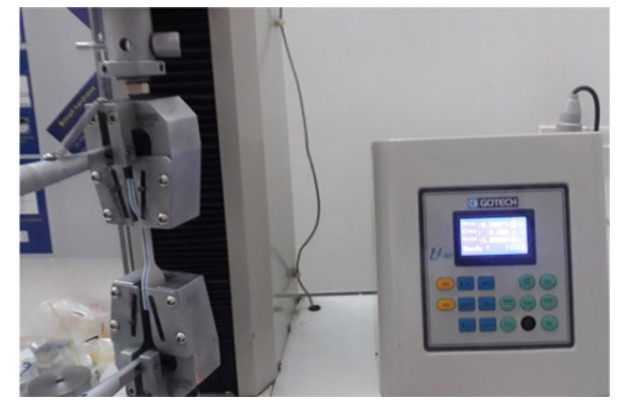

Fig. 7 Coupon testing

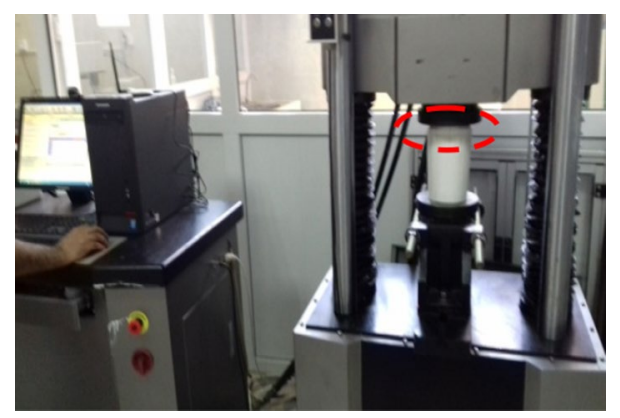

Fig. 8 Testing of the hollow tube
Fig. 9 Test set up
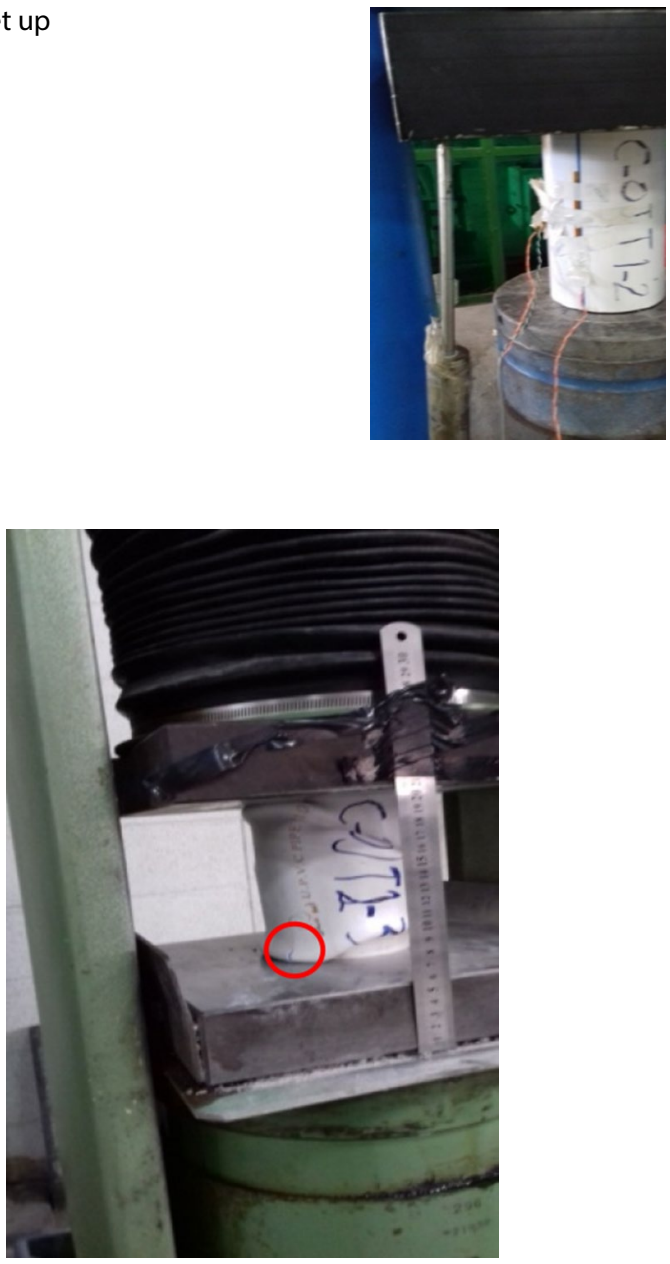

Fig. 10 Ductile failure of C-OJT

displacement at tube mid-height (Fig. 9). The low modulus tube applies continuous pressure on the concrete core until it is containment capacity deteriorates and starts to bulge out under the influence of the crumbled concrete. A slight drop in load indicated the initiation of cracking. C-OJT specimens experienced two peak loads. After the initial failure, the load dropped but began to rise again, rapidly, reaching a value close to the first failure load. Up to considerable deformations and very large strains, the tube remained intact despite significant damages in inner concrete. Once the concrete core crumbled locally, the tubular section stiffness deteriorated and exhibited bulging at several scattered points. However, the test continued until the destruction of the tubular section. A rupture of the plastic tube wall at the point of maximum concrete dilation (bulging), where the material tear and create a small split in the tube wall ( $3 \mathrm{~cm}$ long crack), Fig. 10, this type of failure is ductile. 


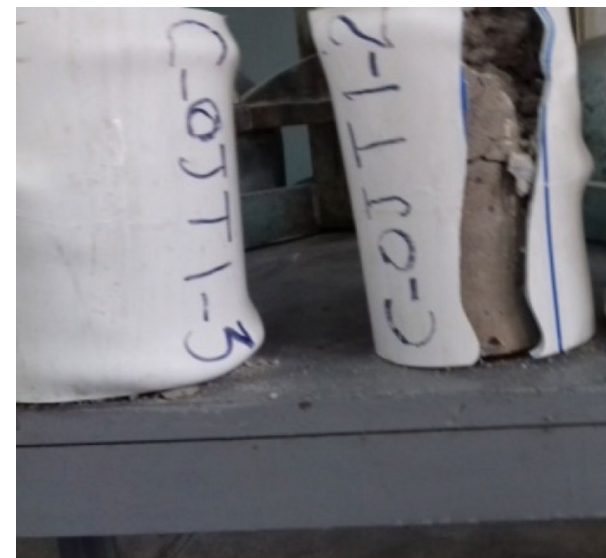

Fig. 11 Brittle failure of C-OJT

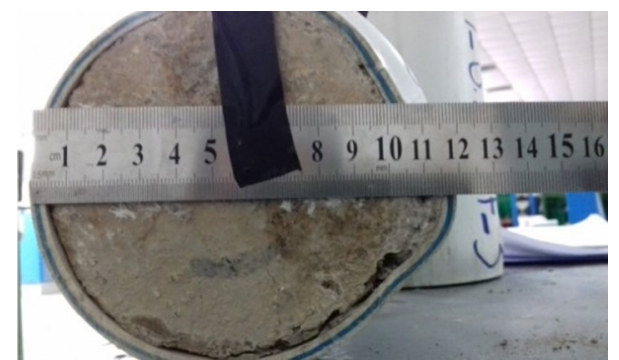

Fig. 12 lateral expansion of C-OJC

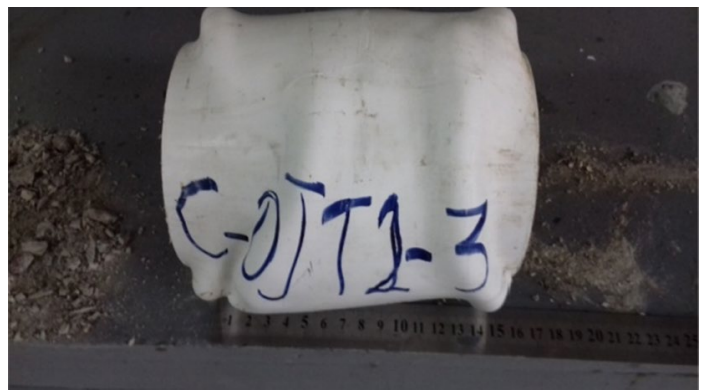

Fig. 13 Nearly $30 \%$ axial shortening of C-OJC

A different kind of failure was the longitudinal cracking of the tube, Fig. 11, a brittle type of failure. The C-OJT specimens underwent considerable lateral expansion, Fig. 12 , nearly $10 \%$. The same change in the axial direction was almost $30 \%$, Fig. 13. Unlike C-OJT specimens, concrete cylinders showed negligible expansion in the two directions resulting in non-ductile failure (Fig. 14). Specimens (C-OJT7-1, C-OJT7-2) with a $20 \mathrm{~mm}$ gap at the top showed different behaviors. The unprotected $20 \mathrm{~mm}$
Fig. 14 Failure of concrete cylinder

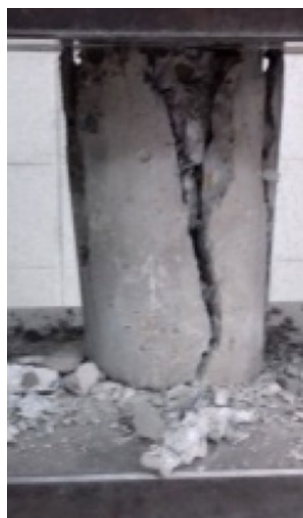

Fig. 15 Failure of C-OJT7-1 with $20 \mathrm{~mm}$ gap

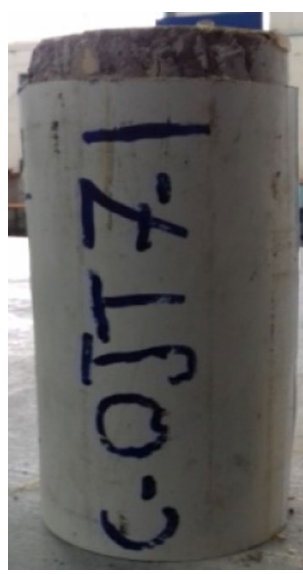

concrete crushed first, followed by the tube deformation (Fig. 15).

\section{Discussions}

The load capacity of the concrete core increased when using the slipping jacket because the latter is more resilient to changes in the external loads, thermoplastic prefabricated jacket can be a potential solution to the threat of external loads such as impact [23]. Due to a gap of 1.2 $\mathrm{mm}$, the plastic jacket with an internal diameter of 102.4 $\mathrm{mm}$ was separated from the concrete core (with an outer diameter of $100 \mathrm{~mm}$ ) resulting in zero adhesive and frictional bonds between the protective jacket and concrete core. At the start of loading, the jacket was not subjected to compression stress in the lateral direction due to zero adhesive bond. With increased loading and concrete dilation, the jacket was stressed in the lateral direction due to the initiation of the frictional bond as the $1.2 \mathrm{~mm}$ separation zone has vanished. After yielding the jacket continued to resist vertical load and contain the lateral expansion of concrete until ultimate failure. 
PVC slip jacket is a technique of adding a secondary element to increase the deformation capacity of the primary load support element. The plastic protective jacket, other than being much lighter than steel jacket and economic, can reduce shrinkage by isolating the concrete core from the surrounding environment and enhance the long term durability of concrete used for infrastructure applications since it's corrosion-resistant [24].

\subsection{Stress-strain relationships}

The stress-strain curves of the C-OJT specimens displayed three zones, elastic, post-yield peak, and plastic zone. Beyond the elastic zone, the specimen sustained considerable load and exhibited first failure at peak load $\left(P_{P_{1}}\right)$, due to the failure of the plastic tube, then the load dropped slightly but started to increase again due to the resistance of concrete core forming a second peak $\left(\mathrm{P}_{\mathrm{P} 2}\right)$ as a result of concrete failure. The second peak was always lower than the first peak (Figs. 16, 17, 18). With the increased microcracks and rupture of concrete, a steady falling branch was formed due to compression softening and the corresponding plastic strain increased. In the plastic zone, some specimens exhibited single or several sudden small drops in the load capacity but quickly recovered (Figs. 16, 17, 18). Column C-OJT1-3 displayed a short plateau following the first peak stress. When concrete cracks, the relation between its lateral and axial strains may no longer be described by Poisson's ratio. The C-OJT specimens demonstrated considerable deformations under the compression load. Plastic deformations result in micro-cracking and softening of the post-peak descending curve. Such deformations allow engineers to consider integrating the jacket in structural components such as bridge columns and piers used in infrastructural applications [25]. Two specimens with a $20 \mathrm{~mm}$ gap at the top, C-OJT7-1 and C-OJT7-2 (Fig. 19), showed similar performance under the axial load and exhibiting two peak loads. The first peak load was due to

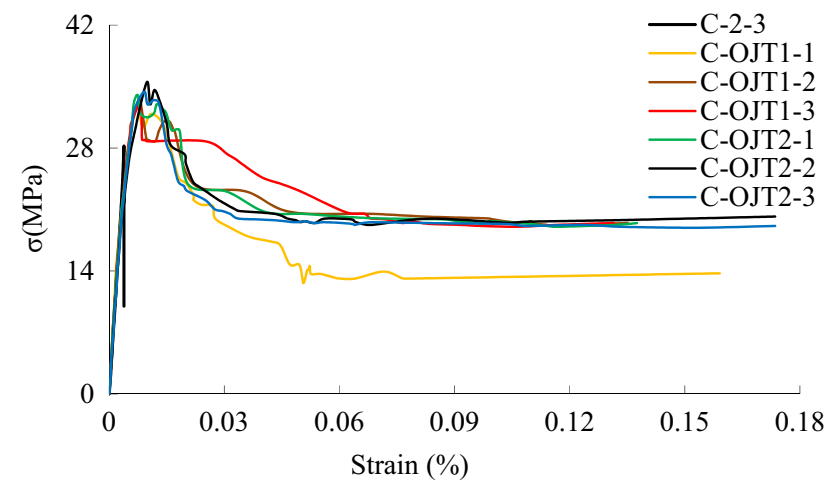

Fig. 16 Stress-strain curve of groups 1-2

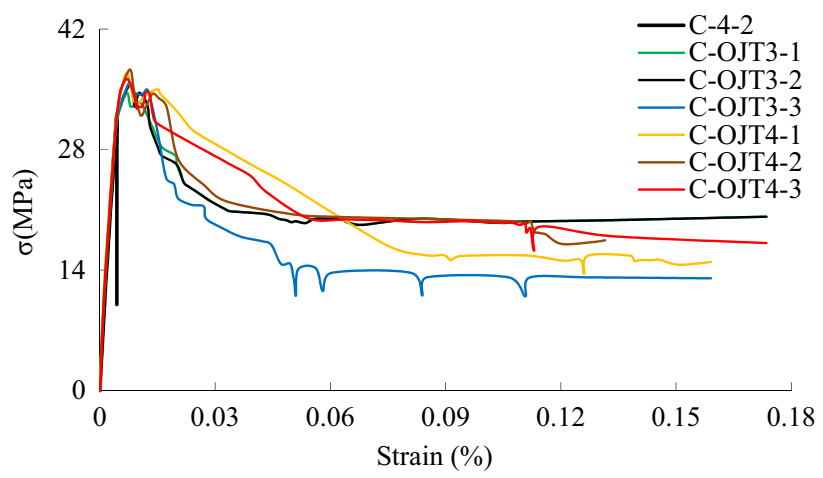

Fig. 17 Stress-strain curve of groups 3-4

the crushing of unprotected concrete (top $20 \mathrm{~mm}$ ). The load dropped slightly but started to increase again, forming the second peak which was higher than the first peak. A similar result was reported previously [25].

The behavior of plain concrete under loading was completely different from that of ductile C-OJT specimens. Specimens without external jacket exhibited a sudden failure after reaching the maximum strain at peak stress, Figs. 16, 17, 18 and 19, showing no deformations in the post peak stage due to the rupture and crumbling of the cement binder.

\subsection{Strength}

The plastic tube acts as spiral reinforcement for concrete structures, such as columns [5]. When axial load is applied, compression stress increases in concrete and the strain reaches its maximum value and concrete cannot support such high deformations. The confining action of the plastic tube is initiated at this stage by introducing passive restraint to dilation of concrete core [26]. This result in considerable enhancement in strength and improvement in ductility of specimens with

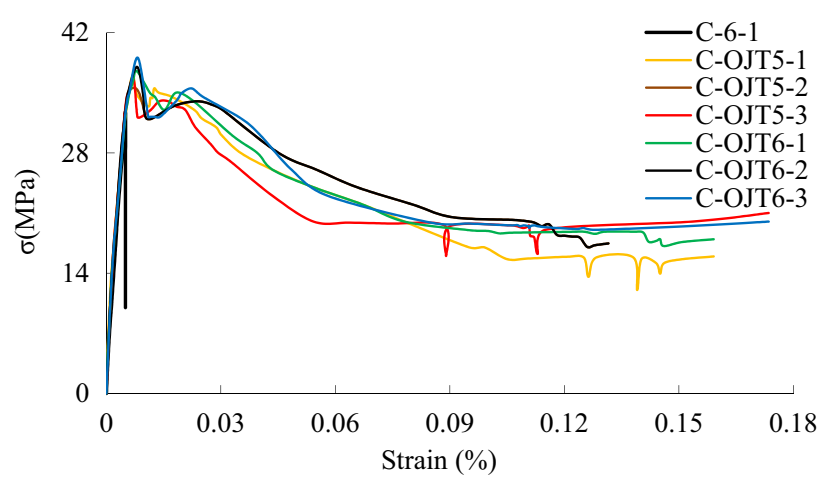

Fig. 18 Stress-strain curve of groups 5-6 
Fig. 19 Stress-strain curve of C-OJT7 specimens

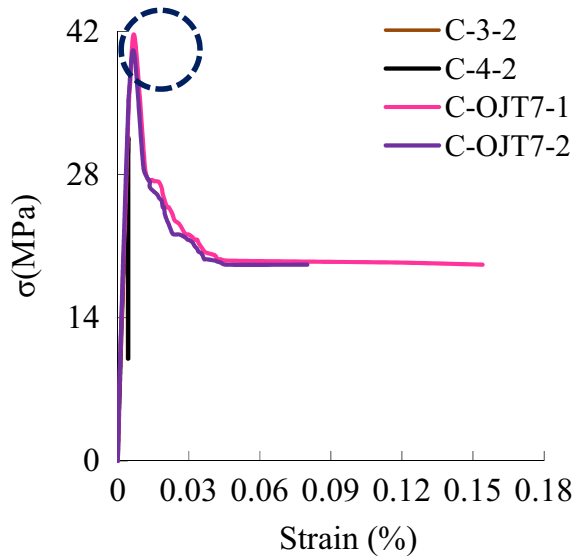

(a) Strain range $0-0.18$

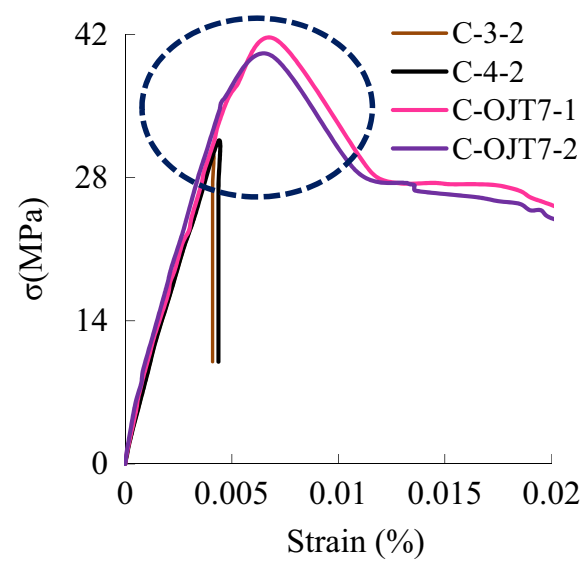

(b) Strain range 0-0.02
Table 2 Test results for strength

\begin{tabular}{|c|c|c|c|c|c|c|}
\hline Specimen & $\mathrm{N}_{\mathrm{CO}}(\mathrm{KN})$ & $\mathrm{N}_{\mathrm{SJ}}(\mathrm{KN})$ & $\mathrm{N}_{\mathrm{CO}}+\mathrm{N}_{\mathrm{SJ}}(\mathrm{KN})$ & $\Delta \mathrm{N}(\mathrm{KN})$ & $\mathrm{N}_{\mathrm{EX}}(\mathrm{KN})$ & $\Delta \mathrm{N} / \mathrm{N}_{\mathrm{EX}}(\%)$ \\
\hline C-OJT1-1 & 215.3 & 50.7 & 266 & 46.6 & 312.6 & 14.91 \\
\hline C-OJT1-2 & & & & 52.9 & 318.9 & 16.59 \\
\hline C-OJT1-3 & & & & 44.2 & 310.2 & 14.25 \\
\hline C-OJT2-1 & 221.6 & 50.7 & 272.3 & 51.2 & 323.5 & 15.83 \\
\hline C-OJT2-2 & & & & 47.7 & 320.0 & 14.9 \\
\hline C-OJT2-3 & & & & 54.9 & 327.2 & 16.78 \\
\hline C-OJT3-1 & 237.7 & 50.7 & 288.4 & 40.6 & 329.0 & 12.34 \\
\hline C-OJT3-2 & & & & 40.0 & 328.4 & 12.18 \\
\hline C-OJT3-3 & & & & 51.4 & 339.8 & 15.13 \\
\hline C-OJT4-1 & 248.3 & 50.7 & 299 & 51.3 & 350.3 & 14.64 \\
\hline C-OJT4-2 & & & & 55.6 & 354.6 & 15.68 \\
\hline C-OJT4-3 & & & & 45.1 & 344.1 & 13.10 \\
\hline C-OJT5-1 & 246.7 & 50.7 & 297.4 & 44.5 & 341.9 & 13.02 \\
\hline C-OJT5-2 & & & & 40.8 & 338.2 & 12.06 \\
\hline C-OJT5-3 & & & & 50.3 & 347.7 & 14.47 \\
\hline C-OJT6-1 & 257.1 & 50.7 & 307.8 & 48.7 & 356.5 & 13.66 \\
\hline C-OJT6-2 & & & & 53.9 & 361.7 & 14.90 \\
\hline C-OJT6-3 & & & & 63.5 & 371.3 & 17.10 \\
\hline C-OJT7-1 & 237.7 & - & 237.7 & 76.4 & 314.1 & 24.32 \\
\hline C-OJT7-2 & 248.3 & - & 248.3 & 77.6 & 325.9 & 23.81 \\
\hline
\end{tabular}

plastic jacket compared with normal concrete specimens. Table 2 summarizes test results for strength capacity. The stub columns showed an increase in compressive strength due to the plastic tube containment. The individual axial strength contributions of the concrete core $\left(\mathrm{N}_{\mathrm{CO}}\right)$ and plastic tube $\left(\mathrm{N}_{\mathrm{SJ}}\right)$ was calculated from Eqs. (1) and (2), and the tube effect $(\Delta N)$ was determined from Eq. (3) [13]. The protective tube resulted in 12.06-17.1\% increase in the experimental test results $\left(\mathrm{N}_{\mathrm{EX}}\right)$, where $\mathrm{N}_{\mathrm{EX}}$ is the ultimate load carried by the C-OJT specimens. Such enhancement attributed to the better strength and toughness of the white multi-layered tube with one blue layer in-between $[2,27]$.
$\mathrm{N}_{\mathrm{CO}}=\frac{\pi}{4}\left(D_{e x}^{2}\right) \cdot f_{c}^{\prime}$

$\mathrm{N}_{\mathrm{SJ}}=\frac{\pi}{4}\left(D_{e x}^{2}-D_{\text {int }}^{2}\right) \cdot f_{y p}$

$\Delta \mathrm{N}=\mathrm{N}_{\mathrm{EX}}-\left(\mathrm{N}_{\mathrm{CO}}+\mathrm{N}_{\mathrm{SJ}}\right)$

where $D_{e x}$ and $D_{\text {int }}=$ the external and internal diameter of the plastic jacket, $f_{c}^{\prime}=$ strength of unconfined concrete, $f_{y p}=$ the yield strength of plastic jacket. 


\subsection{Ductility}

Ductility signifies plastic deformations without considerable loss of strength. This parameter is suitable to qualify the ductility of the C-OJT specimens. To further characterize the strain-softening of C-OJT, an ultimate strain corresponding to the failure strain $\left(\Delta_{P_{4}}\right)$ determined for the tested specimens. For the current study, ductility represented the energy absorbed by the specimen up to its failure (end of testing). Several studies have used the loadaxial deformation relationship to evaluate the energy dissipation capacity of compression members $[28,29]$.

Idealized elastic perfectly plastic load-axial deformation curves used to evaluate the yield stress and strain (Fig. 20), and also the deformation at a stress of $0.75\left(\sigma_{P 1}\right)$,

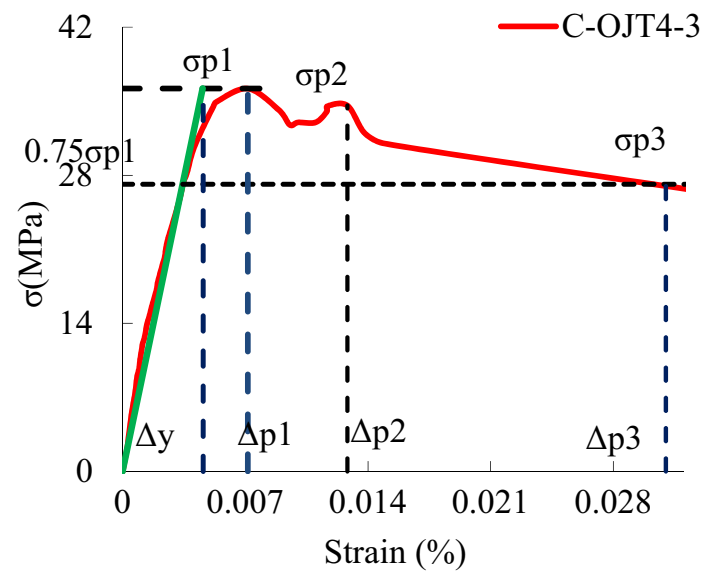

Fig. 20 Determination of $\Delta y, \Delta p 1, p 2 \Delta, p 3 \Delta$ corresponding to $75 \%$ of the first peak axial stress [30]. In Fig. 20; $\Delta_{y}$ and $\Delta_{P 1}, \Delta_{P 2}, \Delta_{P 3}$ represent the axial yielding, first, second, and third peak strains corresponding to yield stress $\left(\sigma_{y}\right)$, first peak stress $\left(\sigma_{P 1}\right)$, second peak stress $\left(\sigma_{P 2}\right)$, and third peak stress $\left(\sigma_{P 3}\right)$ respectively. All the strains $\Delta_{P 1}, \Delta_{P 2}, \Delta_{P 3}$ were smaller than the failure strain $\Delta_{P 4}$. The third peak stress $\sigma_{P 3}$ was taken equal to $0.75\left(\sigma_{P 1}\right)$ on the descending branch of stress-strain curve. Three strain ratios were computed; $\Delta_{y} / \Delta_{P_{1}}, \Delta_{y} / \Delta_{P_{2}}$, and $\Delta_{y} / \Delta_{P_{3}}$ and depicted in Fig. 21. The $\Delta_{y} / \Delta_{p_{1}}$ ratio varied from 0.518 to 1.011. Lower ranges observed for $\Delta_{y} / \Delta_{P_{2}}$ and $\Delta_{y} / \Delta_{P 3}$ ratios. The $\Delta_{y} / \Delta_{P 2}$ ratio varied from 0.219 to 0.654 and the $\Delta_{y} / \Delta_{P 3}$ ratio ranged from 0.114 to 0.317 . The lower $\Delta_{y} / \Delta_{P 3}$ ratio, the better the deformation capacity and ductility of the specimen.

The variations in the stress ratios $\left(\sigma_{y} / \sigma_{P 1}\right),\left(\sigma_{y} / \sigma_{P 2}\right)$, and $\left(\sigma_{y} / \sigma_{P 3}\right)$ for tested specimens plotted in Fig. 22 . The ratio $\sigma_{y} / \sigma_{P 1}$ ranged from 0.793 to 0.899 , which signifies that the tube yielded at a load equal to $0.8-0.9$ of the ultimate load (first peak load), except for the specimens with a $20 \mathrm{~mm}$ gap, which exhibited a higher $\left(\sigma_{y} / \sigma_{P 1}\right)$ ratio of 0.98 , since the first peak stress was lower than the second peak stress. The $\sigma_{y} / \sigma_{P 2}$ ratio was close to one and slightly higher than the ratio $\sigma_{y} / \sigma_{P 1}$. The $\sigma_{y} / \sigma_{P 3}$ ratio was always greater than 1 for all the specimens.

\section{Conclusion}

Designers must look for alternative means to cause a structural member to exhibit ductile deformations. Brittleness, One of the inherent properties of concrete,

Fig. 21 Graph of strain ratios

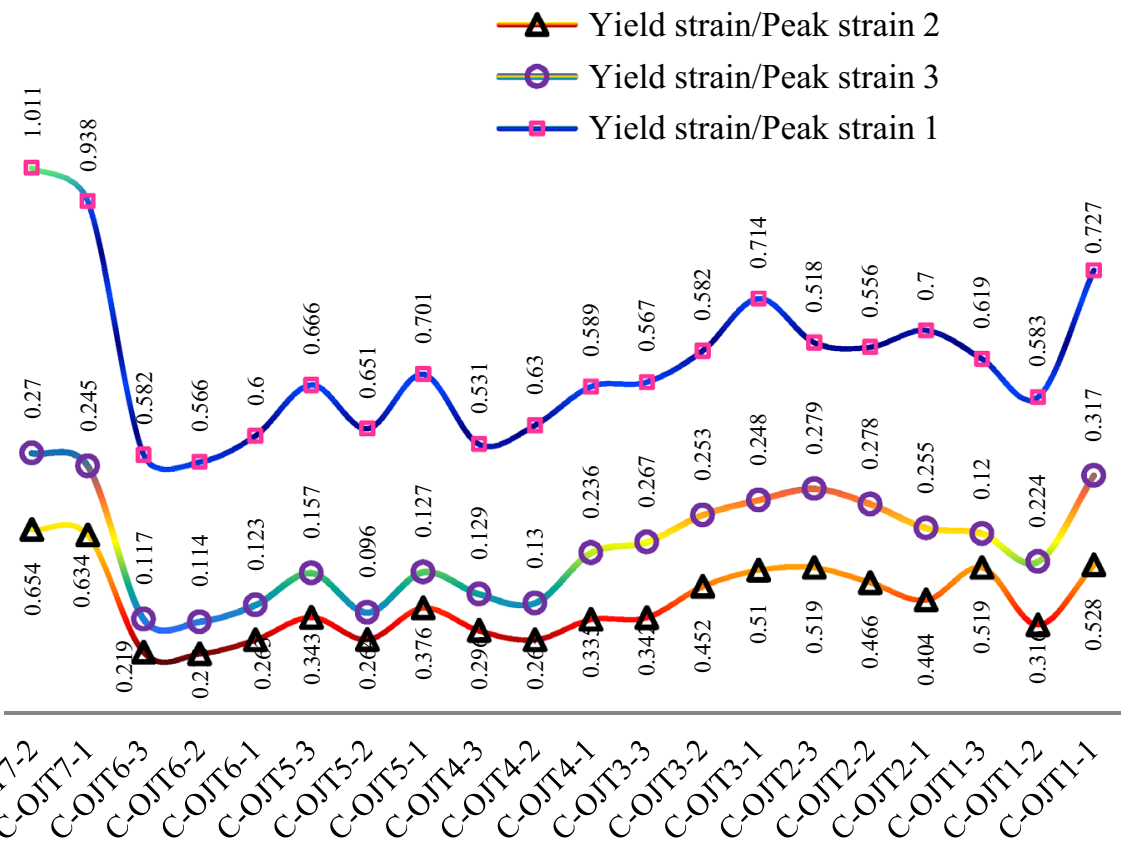

SN Applied Sciences 
Fig. 22 Graph of stress ratios
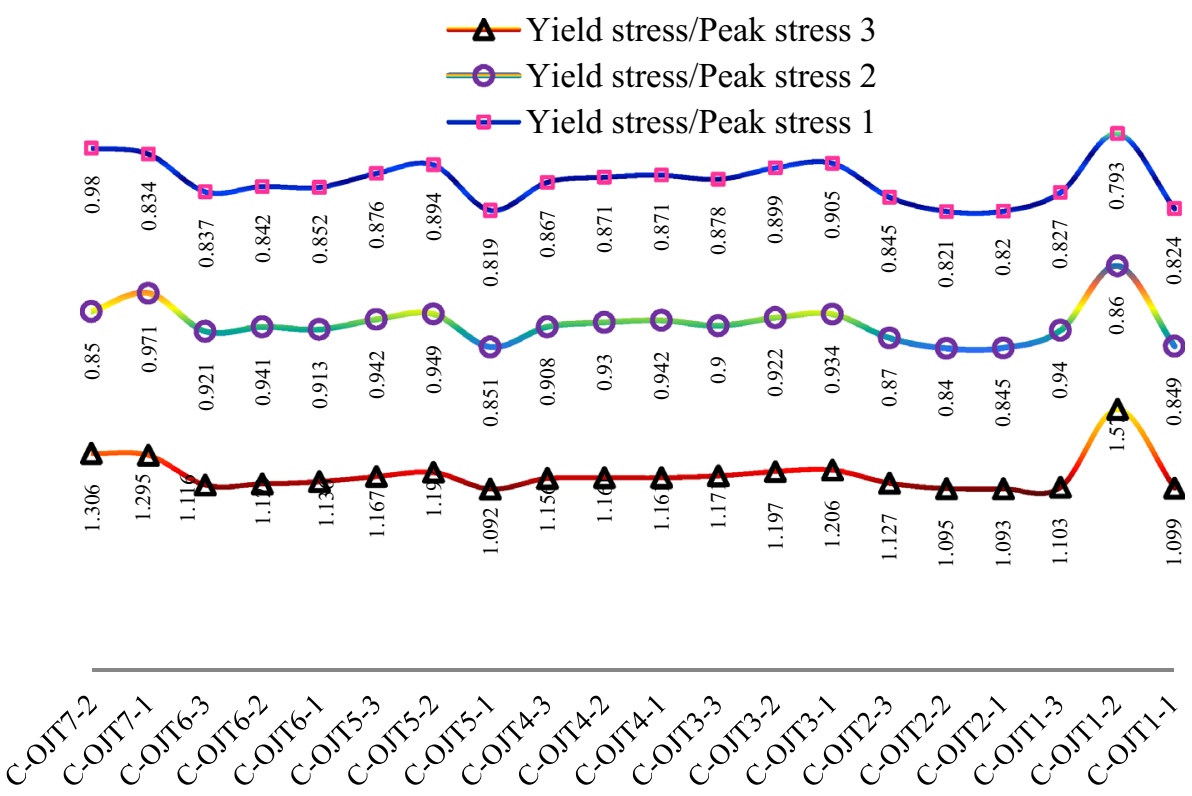

can be handled using the polymeric jacket. The present study focused on the ability of tubular thin-walled composite circular tubes to absorb energy when loaded in compression. The following conclusions can be drawn:

1 The C-OJT specimens absorbed energy by plastic deformation and underwent compression softening represented by the descending branch of the stressstrain curve.

2 The jacketed specimens reached compressive yielding at about $80-90 \%$ of failure load (peak load). The lower $\Delta_{y} / \Delta_{P 3}$ ratios, $0.114-0.317$, showed the better deformation capacity and improved ductility of the tested specimen.

3 Polymeric slip jacket is a technique of adding a secondary element to increase the deformation capacity of the primary load support element. In practice, a self-leveling grout may be adopted to fill the gap between the tube and concrete, thereby helping in adding strength to the compression element, increase its deformation extent, and upgrade its load capacity.

Such a technique may have an impact on the potential use of polymeric tube in civil infrastructure applications. New studies need to consider other jacket parameters such as jacket thickness and strength.

\section{Compliance with ethical standards}

Conflict of interest The authors declares that he/she has no conflict of interest.

\section{References}

1. Masuelli MA (2007) Introduction of fiber-reinforced polymerspolymers and composites. Burgoyne, C., Balafas, I., 2007. Why is FRP not a financial success? In: Proceedings of 8th international conference on FRP reinforcement for reinforced concrete structures. FRPRCS-8, University of Patras, Patras, Greece

2. Hollaway LC (2011) Key issues in the use of fiber-reinforced polymer (FRP) composites in the rehabilitation and retrofitting of concrete structure. In: Karbhari VM, Lee LS (eds) Service life estimation and extension of civil engineering structures. Woodhead Publishing Limited, Abington Hall

3. Sonnenschein R, Gajdosova K, Holly I (2016) FRP composites, and their using in the construction of bridges. Procedia Eng 161:477-482

4. Lu Y, Li N, Li S (2014) Behavior of FRP-confined concrete-filled steel tube columns. Polymers 6:1333-1349

5. Kurt EC (1978) Concrete filled structural plastic columns. In: Proceedings ASCE104 ST1 55-63

6. Abdulla NA (2020) Mechanical behavior of slender composite columns under axial compression load. KSCE J Civ Eng 24(1):208-218

7. Lu JQ, Tian Y, Chen JG, Lu JQ, Tian Y, Chen JG, Wang W (2019) Experimental study on CFRP-PVC confined RAC under axial compression. Solid State Phenom 294:143-149

8. Mahmood A, Al-Badrany AA, Rzayyig AA (2015) The numerical simulation of axial crumpling in grooved circular PVC tubes under static compression. J Eng Sci Technol 10(10):1350-1360

9. Albermani F, Goh GY, Chan SL (2007) Lightweight bamboo double layer grid system. Eng Struct 29:1499

10. John W, Adedeji AA (2018) Reliability assessment of reinforced concrete beam with embedded PVC pipes below the neutral axis. Int J Multi Sci Eng 9(1):9-18

11. Al-Gasham TSS (2015) Reinforced concrete moderate deep beams with embedded PVC pipes. Wasit J Eng Sci 3(1):19-29

12. Yuan WB, Ma SL (2012) Experimental study on concrete-filled steel tubular with external octagon steel tube and inner 
circle PVC-U pipe under axial compression. Adv Mater Res 368-373:511-514

13. Wang J, Yang Q (2010) Experimental study on mechanical properties of concrete confined with plastic pipe. ACI Mater J 107(2):132-137

14. Kurtoglu AE, Hussein AK, Gulsan ME (2018) Mechanical investigation and durability of HDPE-confined SCC columns exposed to severe environment. KSCE J Civil Eng 22:5046

15. Gupta PK, Verma VK (2014) Study of concrete-filled un-plasticized poly-vinyl chloride tubes in the marine environment. Proc Inst Mech Eng Part M J Eng Marit Environ. 1475090214560448

16. Verma VK, Chawla TS, Adhikari M, Sella R (2015) Use of concretefilled un-plasticized polyvinylchloride tubes (CFUT) as a column in polyhouse. Int J Eng Res Technol 4(12):578-582

17. Abdulla NA (2019) Influence of plastic pour-in form on the mechanical behavior of concrete. Structures 19:193-202

18. Lee SWR, Li Z, Tang JM, Lee S, Tong P (1999) Development of composite grid tubes for the reinforcement of concrete columns. ICCM12 conference Paris paper 549. ISBN 2-9514526-2-4

19. Saadoon AS (2010) Experimental and theoretical investigation of PVC-concrete composite columns. Doctoral dissertation, University of Basrah, Iraq

20. Abdulla NA (2014) Concrete filled thermoplastic tube under compression. International engineering conference, Ishik university, pp 60-70

21. Oyawa WO, Gathimba WO, Mang'uriu GN (2016) Structural response of composite concrete-filled plastic tubes in compression. Steel Compos Struct 21(3):589-604. https://doi. org/10.12989/scs.2016.21.3.589

22. Bandyopadhyay A, Samanta AK, Michel Paul KJ (2019) Assessment of axial capacity of RC stub column confined with unplasticized polyvinyl chloride pipe. J Inst Eng (India) Ser A 26(5-6):1-12

23. Uddin N, Purdue JD, Vaidya U (2008) Feasibility of thermoplastic composite jackets for bridge impact protection. J Aerosp Eng 21(4):259-265

24. Abdulla NA (2017) Concrete filled PVC tube: a review. Constr Build Mater 156:321-329

25. Fakharifar M, Chen G (2016) Compressive behavior of FRPconfined concrete-filled PVC tubular columns. Compos Struct 141:91-109

26. Abdulla NA (2020) The behavior of concrete-filled plastic tube specimens under axial load. Jordan J Civ Eng 14(1):69-81

27. Abdulla NA (2020) Concrete encased with engineering plastics. J Civ Eng Constr 9(1):31-41

28. Tao Z, Han LH, ZhuangHan JP (2007) Axial loading behavior of CFRP strengthened concrete-filled steel tubular stub columns. Adv Struct Eng 10(1):37-46

29. Karimi SK, Tait MJ, El-Dakhakhni WW (2012) Influence of slenderness on the behavior of an FRP-encased steel-concrete composite column. J Compos Constr 16(1):100-109

30. Tao Z, Han LH, Wang DY (2007) Experimental behavior of concrete-filled stiffened thin-walled steel tubular columns. Thin Wall Struct 45(5):517-527

Publisher's Note Springer Nature remains neutral with regard to jurisdictional claims in published maps and institutional affiliations. 